\title{
OFICINAS PEDAGÓGICAS NO AMBIENTE VIRTUAL DE APRENDIZAGEM SOB A PERSPECTIVA DISCENTE: UM ESTUDO DAS LICENCIATURAS PEDAGOGIA E LETRAS
}

\author{
LORENA/SP MAIO/2018
}

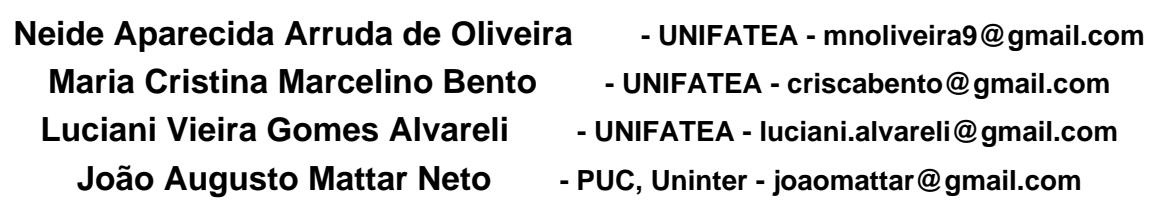

Tipo: Investigação Científica (IC)

Natureza: Planejamento de Pesquisa

Categoria: Pesquisa e Avaliação

Setor Educacional: EDUCAÇÃO SUPERIOR

\begin{abstract}
RESUMO
O estudo apresentado é parte de um projeto de pesquisa denominado Propósito do uso do Ambiente Virtual de Aprendizagem em Instituição de Ensino Superior Salesiana. Esta pesquisa tem como objetivo apresentar as vivências e aprendizagens por meio do ensino híbrido dos alunos dos cursos de Licenciatura em Letras e em Pedagogia. Os objetivos deste estudo foram: diagnosticar a visão do aluno sobre as Oficinas oferecidas no AVA e verificar quais são os aspectos a serem aperfeiçoados. $E$ posteriormente, comparar os resultados entre os dois cursos. A pesquisa-ação foi realizada com 143 alunos das duas licenciaturas. Observou-se que os sujeitos desejam um aperfeiçoamento quanto à utilização das Oficinas virtuais. Conclui-se que há necessidade em manter o aperfeiçoamento das organizações do material de estudo do AVA.
\end{abstract}

Palavras-chave: Letras. Pedagogia. Ensino Híbrido 


\section{Introdução}

No Brasil, a permissão para que cursos superiores presenciais oferecessem até $20 \%$ de sua carga horária total a distância, desde 2004 (Portaria n. 4.059), acabou incentivando a reflexão e a prática sobre a educação semipresencial. Em função da facilidade de produção de conteúdos e de gestão, muitas instituições optaram por oferecer disciplinas inteiras a distância (uma disciplina de cinco, por exemplo, ou um dia por semana), o que corresponderia ao modelo híbrido. Mas houve experiências diferentes, em que partes de todas as disciplinas foram oferecidas a distância. Atualmente, as instituições de ensino brasileiras perceberam o potencial pedagógico e mercadológico dos cursos em que os alunos vão para as universidades um, dois, três dias por semana (manhã, tarde ou noite) para realizar as atividades on-line; ou podem realizá-las em suas próprias residências de acordo com Mattar (2017). Essas atividades geralmente são organizadas em formato de Oficinas.Nesse estudo pretendeu-se diagnosticar a visão do aluno sobre as Oficinas oferecidas no AVA e verificar quais eram os aspectos a serem aperfeiçoados. Posteriormente, comparou-se os resultados entre os dois cursos de Licenciaturas : Letras (53 alunos) e Pedagogia (90 alunos).A pesquisa-ação foi realizada com 143 alunos das duas licenciaturas de uma instituição de ensino superior Salesiana situada no interior do estado de São Paulo no primeiro semestre de 2018.

\section{Referencial Teórico}

A respeito do ensino superior e a necessidade de mudança Valente $(2014$, p. 79$)$ afirma que:

O ensino superior enfrenta atualmente dois grandes desafios. Um é sobre as salas de aula cada vez mais vazias, ou quando o aluno está presente, ele está fazendo outra coisa diferente do que acompanhar a aula. Outro desafio é a incapacidade de atender a grande demanda do número de alunos que querem ingressar no ensino superior. Assim, o modelo de universidade que faz pesquisa, gera conhecimento e distribui este conhecimento para poucos já não se sustenta mais.

Nesse sentido, é um desafio para as instituições e professores permitir que o maior número possível de estudantes tenha sucesso, dada a grande diversidade do corpo discente. Por isso, é necessário focar em métodos de ensino que levem o aluno a desenvolver as competências e habilidades de acordo com as exigências do século XXI, oferecendo mais empoderamento na aprendizagem por meio de resolução de problemas presentes no cotidiano. Esses desenvolvimentos colocam muito mais responsabilidade sobre os professores e instrutores (bem como, dos estudantes) e exigem um nível muito 
mais alto de habilidades de ensino (BATES, 2016 e pela Conference Board of Canada [2014]).Nesta pesquisa, entende-se que o ambiente de aprendizagem deve ser pensado e organizado como proposto por Mattar (2014) a partir dos fatores: humanos, pedagógicos, físicos ou tecnológicos, abstratos. Esses fatores auxiliam na elaboração do detalhamento dos objetivos de aprendizagem.Considerando as habilidades necessárias ao aprendiz, neste início do século XXI, o advento das tecnologias digitais, somadas à responsabilidade docente do ensino superior, e à necessidade de organizar o ambiente de aprendizagem, subtende-se que o ensino híbrido, aprendizagem híbrida ou também chamada de Blended learning, possa auxiliar na formação do aluno do ensino superior.

\section{Procedimentos Metodológicos}

Este estudo realizou-se por meio da pesquisa-ação, uma vez que esta auxilia a aprimorar a pra?tica pela oscilação sistema?tica entre agir no campo da pra?tica e investigar a respeito dela. Planeja-se, implementa-se, descreve-se e se avalia uma mudança para a melhora de sua pra?tica, aprendendo mais, no decorrer do processo, tanto a respeito da pra?tica quanto da pro?pria investigac?a?o. (TRIPP, 2005).A pesquisa-ação foi desenvolvida a partir de quatro ações: planejar, agir, observar, e refletir, em uma instituição salesiana brasileira, de ensino superior. Essa instituição adota o uso de ambiente virtual de aprendizagem - AVA, pelo viés da educação on-line. O local de pesquisa tem núcleo de educação a distância - NEAD, que oferece oportunidade de formação docente por meio da criação de material digital, utilizando ferramentas e aplicativos desenvolvidos no AVA institucional.Para a elaboração das oficinas virtuais no AVA, efetuaram-se os quatro momentos da pesquisa-ação, a saber: planejar - cada docente escolheu o conteúdo da disciplina e aplicativos para organização da oficina; agir - montagem das oficinas; observar - ocorreu mediante a realização das oficinas e análise das respostas do questionário; reflexão - a análise dos dados coletados por meio do questionário, que proporcionou a reflexão pelo coordenador do curso, equipe NEAD e pelo núcleo docente estruturante do curso para o planejamento e organização de oficinas futuras.O projeto de pesquisa foi aprovado pelo Comitê de Ética em Pesquisa do UNIFATEA, sob Parecer Consubstanciado de no․ CAAE: 85648018.7.0000.543.

Participaram dessa pesquisa 143 discentes (53 de Letras e 90 de Pedagogia.Os dados foram coletados por meio de um questionário, organizado pelos coordenadores da Pesquisa Piloto - autores deste texto, que continha quinze questões, sendo catorze fechadas, de múltipla escolha, e uma aberta. As questões fechadas eram sobre o perfil do sujeito e a organização da oficina. As questões fechadas referiram-se a mapear: 
sexo; idade; local onde reside; se possui algum tipo de bolsa de estudo, se sim, qual seria; como o aluno realizou a oficina pelo computador ou celular; quantas realizou; como as oficinas podem ser classificadas quanto à qualidade; quanto ao conteúdo; o design da mesma; o volume do conteúdo; qualidade das questões e coerência do que foi solicitado com o que foi dado em sala de aula. Já a questão aberta consistia em saber o que poderia ser melhorado e poderia o discente dar suas sugestões. $O$ trabalho aqui apresentado é resultado do olhar discente de alunos sobre a produção de oficinas virtuais realizada pelos docentes do curso de Letras e Pedagogia mediante a ampliação da sala de aula, por meio do uso do AVA institucional.

\section{Apresentação e Discussão dos Resultados}

\subsection{Curso de Letras}

Passando à análise dos dados, a primeira questão estava relacionada a saber quantos discentes eram do sexo masculino e feminino. Dos 53 alunos que participaram da pesquisa, 31 eram do sexo feminino e 22 do masculino. Há um percentual maior de mulheres que o dos homens no curso de Licenciatura em Letras. Esse dado é confirmado por outras pesquisas que mostram a predominância das mulheres na área do magistério. $\mathrm{Na}$ segunda questão, solicitou-se aos discentes que assinalassem a idade. Essa questão foi inserida de modo que se pudesse verificar se a relação idade e estudo de forma híbrida são fatores relevantes no preparo do material das aulas. Vinte e sete discentes estão entre 19 a 24 anos de idade; sete possuem idade entre 25 a 29 anos, doze alunos assinalaram estar acima de 29 anos, seis discentes com 18 anos completos e apenas um discente menor de dezoito anos. No que se refere à terceira questão, com a intenção de verificar o local de residência dos alunos, de modo que pudéssemos entender o estudo de forma híbrida do aluno que trabalha, viaja e estuda, solicitou-se que assinalassem o nome da cidade onde residem: 25 moram em Lorena, treze moram em Guaratinguetá, cidade localizada a $12 \mathrm{~km}$ da cidade da IES; três de Piquete, outros três em Potim e quatro de Cruzeiro, dois em Aparecida, um em Roseira, um na cidade de Cunha e um em Pinda.A quarta e a quinta questões ofertadas aos discentes foram sobre bolsas de estudo, se tinham ou não e se tinham, qual era o tipo de bolsa de estudos. Trinta e três sujeitos disseram que tinham bolsa de estudo e 20 disseram não possuir.Quanto aos tipos de bolsas de estudo, as bolsas assinaladas foram PROUNI, PIBID, FIES, EDUCA MAIS, ESCOLA DA FAMÍLIA, Quero SER UNIFATEA, bolsa de Mérito - oferecida pela prefeitura, bolsa para Funcionário da IES e Município. Alguns discentes possuíam mais de uma bolsa.A sexta questão referiu-se a qual meio tecnológico o discente realizou as oficinas no AVA. Os meios utilizados foram: notebook, computador próprio, celular, computador da instituição de ensino e tablet. 
Muitos alunos marcaram mais de um meio tecnológico.A sétima questão indagava aos discentes se eles realizaram todas as oficinas, apenas algumas, algumas institucionais ou todas as oficinas institucionais. Os 53 alunos que responderam o questionário afirmaram que realizaram todas as disciplinas. A oitava questão refere-se a como os discentes classificavam as oficinas, em geral. As alternativas para a resposta eram: ótimas, boas, regulares e ruins. Trinta e um disseram que são boas; dez, regulares; nove discentes afirmaram ser ótimas as oficinas e três disseram ser ruins. A nona questão refere-se ao conteúdo das oficinas oferecidas aos discentes. O conteúdo das oficinas pode ser considerado bom, pois 39 discentes assim registraram, nove assinalaram como ótimo, cinco avaliaram como regular e nenhum discente avaliou as oficinas como ruim.A décima questão refere-se à apresentação dos conteúdos da oficina, ao design da mesma. Trinta e um discentes afirmaram ser boa a apresentação, treze declararam ser ótima, seis disseram que são regulares e três afirmaram ser ruim.A questão seguinte do questionário estava relacionada à quantidade, ao volume do conteúdo das oficinas. Quanto ao volume, os discentes poderiam assinalar como: grande, adequado e pequeno. Trinta e oito discentes afirmaram estar adequado os conteúdos oferecidos pelas oficinas, treze declararam ser grande o conteúdo, ou seja, extenso, e dois disseram ser conteúdos pequenos.A décima segunda questão solicitava aos discentes se eles consideravam o conteúdo das oficinas como algo novo, se era complementar aos conteúdos dados em sala de aula, ou se era repetitivo, porém necessário para reforçar os conteúdos estudados em sala de aula. Trinta e sete discentes afirmaram que os conteúdos das oficinas complementavam os conteúdos dados em sala, oito declararam ser repetitivos, quatro disseram ser conteúdos novos e quatro relataram ser conteúdos repetitivos, porém necessários.Cada oficina continha um questionário com perguntas fechadas que apresentava o feedback do discente ao término da mesma, quando perguntado aos discentes se todas as informações solicitadas estavam no questionário, obteve-se como resultado: 37 afirmaram estar adequados o questionário, dez afirmaram ser muito extenso, quatro disseram ser extenso, mas adequado e dois discentes afirmaram ser pequeno.A décima quarta pergunta era se todas as informações solicitadas no questionário estavam elaboradas de forma explícita, implícita ou não constavam no material da oficina. Vinte e três discentes afirmaram que as informações estavam explícitas, nove disseram que não estavam explícitas e um discente relatou que não estava no material fornecido pela oficina.Na última questão do questionário respondido pelos discentes, foi perguntado 0 que poderia ser melhorado nas oficinas. Era uma pergunta aberta. Vinte e três discentes afirmaram que a apresentação das oficinas precisava melhorar, que o design não é atrativo. Doze afirmaram que as oficinas devem complementar os conteúdos dados em sala de aula; cinco afirmaram que se necessita estabelecer um limite padrão de questões, ou seja, há oficinas em que há muitas questões e outras menos, há 
necessidade de haver um equilíbrio. Outros cinco alunos disseram ser necessário adequar os conteúdos apresentados nas oficinas aos dados em sala de aula. Quatro discentes relataram que deveriam aparecer as questões certas e erradas após eles terem finalizado as questões. Três discentes afirmaram que há embaralhamento de questões e respostas. E um discente declarou que poderia melhorar a acessibilidade das oficinas.Cabe ressaltar que as Oficinas era uma atividade obrigatória a ser realizada pelos discentes e as notas obtidas faziam parte do conjunto de notas que comporiam a média semestral.

\subsection{Curso de Pedagogia}

Os dados revelam que o curso de Pedagogia continua a ser mais procurado por sujeitos do sexo feminino; participaram desta pesquisa 6 sujeitos do sexo masculino e 84 do feminino.Pode-se afirmar que os sujeitos são jovens; onze tinham 18 anos; cinquenta e três alunos possuíam de 19 a 25 anos; dez tinham de 26 a 29 anos e dezesseis possuíam mais de 29 anos.Pautados no alargamento da sala de aula, pela possibilidade do ensino híbrido, buscou-se conhecer o local de residência dos sujeitos, identificando que 49 residem no município do local de pesquisa e 40 em cidades circunvizinhas.Sessenta e cinco sujeitos possuem bolsa de estudo, ofertadas pelo governo federal ou estadual, particulares ou pela própria instituição.Lembrando que as oficinas são organizadas a partir de diferentes tipos de dispositivos, foi solicitado aos sujeitos que assinalassem o tipo de dispositivo que o discente utilizou para realizar as oficinas. Notebook é o dispositivo mais utilizado pelos sujeitos - 47 , seguidos do computador - 30 , oito sujeitos utilizam o computador do laboratório da instituição, 5 sujeitos utilizaram o celular.A realização da maior parte das oficinas era uma atividade obrigatória a ser realizada pelos discentes e as notas obtidas faziam parte do conjunto de notas para a média semestral. Ao serem indagados sobre a realização das mesmas, setenta e oito alunos afirmaram que realizaram todas as oficinas obrigatórias. Doze realizaram algumas das obrigatórias. Sobre as oficinas institucionais optativas, 4 sujeitos afirmaram ter realizado algumas. O conteúdo das oficinas foi classificado por vinte e um sujeitos como ótimo; cinquenta e quatro registraram bom, quatorze apontaram como razoável e um sujeito sinalizou como ruim. Foi solicitado aos sujeitos, que também, classificassem o conteúdo como novo, complementar, repetitivo ou repetitivo e necessário. Nove sujeitos entenderam o conteúdo como novo. Em relação à sua formação; setenta e dois classificaram como complementar ao seu processo de formação mediante aos conteúdos estudados em sala de aula e nove classificaram como repetitivo, porém necessário.A forma de apresentação do conteúdo foi considerada como ótima para vinte e sete sujeitos, quarenta e seis consideram boa, quinze marcaram como razoável e dois sinalizaram como ruim.A quantidade de 
conteúdo de cada oficina foi classificada como muito por 28 sujeitos; adequado por 50 sujeitos e pouco por 12 sujeitos.A penúltima questão solicitava aos sujeitos assinalar como perceberam a informação solicitada nas questões em relação ao conteúdo. Trinta e um sujeitos perceberam que as informações estavam implícitas no conteúdo das oficina e cinquenta e nove afirmaram estar explícitas. A última questão era aberta, o que permitia aos sujeitos expressar comentários que não foram possíveis nas demais questões fechadas. Sendo assim, puderam dar sugestões para cada uma das nove oficinas obrigatórias que cada sujeito teve que realizar. Ressalta-se que esta não era uma questão obrigatória, mas cinquenta e dois sujeitos responderam.

\subsection{Comparativo das Oficinas nos cursos de Letras e Pedagogia}

Passar-se-ão às comparações verificadas no questionário composto por 14 questões de múltipla escolha e uma aberta respondidas pelos 143 alunos das duas licenciaturas. $O$ questionário pode ser diagnosticado em duas categorias: verificação do perfil dos alunos das duas licenciaturas e avaliação das oficinas no AVA.Inicialmente foi feita a verificação do perfil como segue. Comparando os dois grupos de discentes dos diferentes cursos, registramos que em ambos há um número superior de estudantes do sexo feminino a do masculino. Em Pedagogia são 84 mulheres e 6 homens e Letras 31 e 22 respectivamente. Esse dado é confirmado por outras pesquisas que mostram a predominância das mulheres na área do magistério.Em relação à faixa etária, constatouse que os alunos possuem a mesma faixa etária com pequena variação verificando a porcentagem, conforme tabela abaixo.

\begin{tabular}{|l|l|l|}
\hline Faixa etária & Letras (53 alunos) & Pedagogia (90 alunos) \\
\hline Menor que 18 anos & $01(2 \%)$ & 0 \\
\hline 18 anos completos & $06(11 \%)$ & $11(12 \%)$ \\
\hline Entre 19 e 24 & $27(51 \%)$ & $53(59 \%)$ \\
\hline Entre 25 e 29 & $07(13 \%)$ & $10(11 \%)$ \\
\hline Acima de 29 & $12(23 \%)$ & $16(18 \%)$ \\
\hline
\end{tabular}

Em relação aos locais, em ambos os cursos, os alunos moram na cidade onde estudam ou nos municípios situados circunvizinhos, aproximadamente $70 \mathrm{~km}$ de distância.Sobre receber bolsas de estudo, de 90 alunos, 65 recebem bolsas em Pedagogia. Em Letras, de 53 alunos, 33 são bolsistas e 20 não. Estas bolsas são ofertadas pelo governo federal ou estadual, particulares ou pela própria instituição. Ou seja, $72 \%$ dos discentes recebem bolsa de estudo em Pedagogia e 62\% de Letras. Verifica-se que embora a mensalidade do curso seja a mais acessível, $10 \%$ a mais dos alunos recebem bolsas de estudo em Pedagogia.O meio tecnológico mais utilizado para realizar as Oficinas no 
AVA foi o notebook, o que corrobora que os universitários já utilizam o equipamento tecnológico mais individualizado.As Oficinas foram realizadas pela maioria dos alunos, pois eram obrigatórias e faziam parte do conjunto de notas que comporiam a média semestral.Passemos a segunda categoria do questionário aplicado referentes: à qualidade, ao design, ao volume e coerências das Oficinas oferecidas aos alunos.Quanto à avaliação geral das Oficinas, apresentou a seguinte avaliação:

\begin{tabular}{|l|l|l|}
\hline Avaliação geral & Letras (53 alunos) & Pedagogia (90 alunos) \\
\hline Ótima & $09(19 \%)$ & $21(24 \%)$ \\
\hline Boa & $31(60 \%)$ & $54(60 \%)$ \\
\hline Regular & $10(20 \%)$ & $14(16 \%)$ \\
\hline Ruim & $03(1 \%)$ & $01(1 \%)$ \\
\hline
\end{tabular}

Em geral, a avaliação é considerada boa, podendo melhorar. Aqui surge o seguinte questionamento: em que elas poderiam ser melhoradas? Segue-se, então, a leitura e reflexão atenta aos itens mais específicos do questionário.Quanto à apresentação do conteúdo, apresentou-se os seguintes dados:

\begin{tabular}{|l|l|l|}
\hline Apresentação & Letras (53 alunos) & Pedagogia (90 alunos) \\
\hline Ótima & $13(26 \%)$ & $27(30 \%)$ \\
\hline Boa & $32(61 \%)$ & $46(52 \%)$ \\
\hline Regular & $06(12 \%)$ & $15(17 \%)$ \\
\hline Ruim & $03(1 \%)$ & $02(1 \%)$ \\
\hline
\end{tabular}

Nesta avaliação, apareceram algumas solicitações quanto à melhoria no design das Oficinas. Na fala de um aluno, é demonstrada a necessidade de inserir imagens que complementem o conteúdo, ele ainda relata "faltou mais imagens, ou seja, equilíbrio entre texto imagens". O conteúdo não pode ser muito longo, uma vez que os discentes afirmam: "trabalhamos dia todo, estudamos à noite e ainda temos oficina para fazer"; essas palavras remetem à necessidade de auxiliar o docente que utiliza o AVA como alargamento da sala de aula.Quanto à quantidade, quanto ao volume, constatou-se que em abos os cursos houve um consenso quanto ao volume das informações.

\begin{tabular}{|l|l|l|}
\hline Volume das informações & Letras (53 alunos) & Pedagogia (90 alunos) \\
\hline Grande & $13(25 \%)$ & $32(30 \%)$ \\
\hline Adequado & $38(72 \%)$ & $50(56 \%)$ \\
\hline Pequeno & $02(4 \%)$ & $12(14 \%)$ \\
\hline
\end{tabular}

Quanto ao conteúdo das Oficinas, se ele é complementar ao que foi dado em sala de 
aula, se foi repetitivo (porém necessário para reforçar) ou se foi novo (não foi estudado em sala de aula), a maioria de ambos os cursos afirmou que os conteúdos das Oficinas foram complementares aos dados em sala de aula, conforme tabela abaixo:

\begin{tabular}{|l|l|l|}
\hline Conteúdo & Letras (53 alunos) & Pedagogia (90 alunos) \\
\hline Complementar & $37(70 \%)$ & $72(80 \%)$ \\
\hline Novos & $4(8 \%)$ & $9(10 \%)$ \\
\hline Repetitivos & $12(23 \%)$ & $9(10 \%)$ \\
\hline
\end{tabular}

Ao final de cada Oficina, havia um questionário a ser respondido pelos alunos quanto às informações, se estavam explícitas, implícitas ou não constavam no conteúdo oferecido pelas disciplinas. Nem todos os alunos do curso de Letras responderam o questionário.

\begin{tabular}{|l|l|l|}
\hline Coerência & Letras (33 alunos) & Pedagogia (90 alunos) \\
\hline Explícitas & $23(70 \%)$ & $59(66 \%)$ \\
\hline Implícitas & $9(27 \%)$ & $31(35 \%)$ \\
\hline Não estava no material & $1(3 \%)$ & $0(0 \%)$ \\
\hline
\end{tabular}

Para finalizar, houve uma pergunta aberta aos alunos, solicitando que dessem sugestões para a melhoria das Oficinas. Dentre elas destacamos: melhoria do design das Oficinas, devem-se colocarum limite nas questões para que haja um equilíbrio, devese melhorar a acessibilidade, inserir imagens tornando-as mais dinâmicas.

\section{Conclusão}

A presente pesquisa teve como objetivo conhecer a visão dos discentes de um curso de Letras e Pedagogia sobre ambientes virtuais de aprendizagem - AVA que complementam especificamente as atividades de sala de aula desenvolvidas na forma de oficinas virtuais.Mediante a análise dos dados coletados, pôde-se destacar que os discentes valorizaram os conteúdos produzidos pelos docentes, porém apontam a necessidade de aperfeiçoar a preparação das oficinas.A formação docente tecnológica precisa ser processo que busca atender o perfil dos alunos e a necessidade de mercado, para a aprendizagem significativa. $O$ termo aprendizagem significativa foi cunhado por Ausubel (1918-2008), pesquisador norte americano. Para o pesquisador, a aprendizagem deveria se dar de forma subjetiva e a partir do conhecimento prévio do aluno sobre o objeto a ser aprendido. Esta aprendizagem se dá mediante os links que o aluno faz entre o que já sabe com os conhecimentos novos de forma não linear.São onze os princípios e estão fundamentados em seus referenciais teóricos, direcionados às orientações para a organização do material propondo quando/como utilizar 
palavras/imagens/sons/movimento. Afinal, é preciso criar espaços de aprendizagem mais dinâmicos e interativos.Sobre a necessidade das mudanças na organização dos ambientes virtuais de aprendizagem, destaca-se o publicado por Eden Dahlstrom, D. Christopher Brooks (2014, p. 3) que afirma que mais estudantes do que nunca experimentaram um ambiente de aprendizado digital e a maioria diz que aprende melhor com uma mistura de trabalho online e presencial.

\section{Referências}

BATES, T. Educar na era digital: design, ensino e aprendizagem. Tradução: João Mattar et al. São Paulo: Artesanato Educacional, 2016.

CONFERENCE BOARD OF CANADA. 2014. Disponível em : https://www.conferenceboard.ca/?AspxAutoDetectCookieSupport=1, acesso em 30 de abril 2018.

DAHLSTROM, Eden; BICHSEL ,Jacqueline. ECAR Study of Undergraduate Students and Information Technology, 2014. Research report. Louisville, CO: ECAR, October 2014. Disponível em: http://www.educause.edu/ecar, acesso em 30 de abril 2018.

MATTAR, J. A. N. Design Educacional: educação a distância na prática. São Paulo: Artesanato Educacional, 2014.

Metodologias Ativas: para a educação presencial, blended e a distância. São Paulo: Artesanato Educacional, 2017.

MASSETO, M. T. Competência Pedagógica do Professor Universitário. 2 ed. São Paulo: Summus, 2012.

TRIPP, D. Pesquisa-ação: uma introdução metodológica. Tradução de: Oliveira, Lólio. Educação e Pesquisa, São Paulo, v.31, n. 3, set/dez.2005, p. 443-466,

VALENTE, J. A. Blended learning e as mudanças no ensino superior: a proposta da sala. Educar em Revista, Curitiba, Brasil, Editora UFPR. Edição Especial n. 4/2014, p. 79-97. 